\title{
La posverdad: identidades colectivas que degeneran las democracias*
}

\author{
Frank Brady Morales Romero** \\ Renato Rafael Martínez Martínez*** \\ Recibido: 2020-02-17 • Enviado a pares: 2020-03-19 \\ Aprobado por pares: 2020-05-04 - Aceptado: 2020-05-22 \\ https://doi.org/10.22395/angr.v19n37a6
}

\begin{abstract}
Resumen
La presente investigación tiene como objetivo analizar el fenómeno de la posverdad y su influencia en la conformación de una sociedad, cuyo tipo de identidad colectiva otorga gran valor a sus creencias y emociones en la construcción de la opinión pública. Este fenómeno provoca polarizaciones políticas que degradan las democracias en sociedades que excluyen la opinión del que no piensa como el cuerpo colectivo, lo cual se genera especialmente en las redes sociales.

El método que se utiliza en este trabajo es el hermenéutico, ya que permite analizar algunos hechos específicos — que se reconocieron desinteresadamente- con el fin de situar el concepto de posverdad en un contexto político y coyuntural en varios espacios geográficos del mundo. Estos espacios serán interpretados, a su vez, a la luz de la filosofía posmoderna y de la reflexión crítica.

Una de las reflexiones más importantes que ha suscitado esta investigación es que la pretendida objetividad de la epistemología tradicional se ha debilitado aceleradamente ante el hecho de que los sistemas de creencias han cobrado carta de ciudadanía. Estos sistemas presumen certezas en el imaginario colectivo, en el dominio y conocimiento de la realidad, de los hechos, los sentimientos y las intenciones de las personas independientemente de que los juicios correspondan o no correspondan a las cosas. De esta manera, se permite entrever que estos sistemas de creencias desvían al ser humano, al ciudadano común, de la realidad objetiva, lo que lo aleja de un verdadero pensamiento crítico.
\end{abstract}

Palabras clave: posverdad; nihilismo; transparencia; posmodernidad; verdad; poder; voluntad.

\footnotetext{
Este trabajo es el resultado de la investigación interdisciplinar entre dos grupos de investigación: Intellectus Greacus Latinos y su semillero Muisca Nous sobre filosofía de las tecnologías, adscrito a la Facultad De Ciencias Humanas de la Universidad Del Atlántico, Barranquilla, Colombia; y el grupo Verba Luris de la Fundación Universitaria del área Andina, Valledupar, Colombia, que finalizó en el año 2020.

" Magíster en Filosofía, Universidad del Norte, Barranquilla, Colombia. Docente investigador, Universidad del Atlántico, Barranquilla, Colombia. Correo electrónico: frankmorales@mail.uniatlantico.edu.co. Orcid: http://orcid. org/0000-0002-0094-1412

"* Estudiante de maestría en Filosofía, Universidad del Norte, Barranquilla, Colombia. Docente Investigador, Fundación Universitaria del Área Andina, Pereira, Colombia. Líder, Grupo de investigación Verba Iuris, Categoría "C" Colciencias. Correo electrónico: rmartinez41@areandina.edu.co. Orcid: https://orcid.org/0000-0003-4347-4364
} 


\title{
Post-truth: Collective Identities that Degenerate Democracies
}

\begin{abstract}
This research has as its main goal analyzing the post-truth phenomenon and its influence in the conformation of a society whose type of collective identity assigns great value to its beliefs and emotions in the construction of public opinion. This phenomenon creates political polarization that degrades democracies in societies that exclude the opinion of those who does not think as the collective body, which takes place, especially in social networks.

The method employed in this research is the hermeneutic one, given that it allows the analysis of some specific facts - that were recognized indifferently — to locate the post-truth concept in a political context that is conjunctural in several geographical spaces of the world. These spaces will be interpreted in the light of postmodern philosophy and critical reflection.

One of the most important reflections that arise from this research is that the objectivity pretended by the traditional epistemology has rapidly weakened in front of the fact that the belief systems have demanded citizenship. These systems summarize certainties in the collective imaginary, in the realm and knowledge of reality, of facts, of feelings, and intentions of people independently of the fact that judgements correspond or not things themselves. Thus, this allows us to see that these belief systems divert human beings, the common citizen, from objective reality, which also deviates them from truly critical thinking.
\end{abstract}

Keywords: post-truth; nihilism; transparency; post-modernity; truth; power; will.

\section{A pós-verdade: identidades coletivas que degeneram as democracias}

\section{Resumo}

Esta pesquisa tem como objetivo analisar o fenômeno da pós-verdade e sua influência na formação de uma sociedade, cujo tipo de identidade coletiva dá grande valor a suas crenças e emoções na construção da opinião pública. Esse fenômeno provoca polarizações políticas que degradam as democracias em sociedades que excluem a opinião dos que não pensam como o corpo coletivo, o que é gerado especialmente nas redes sociais. O método utilizado neste trabalho é o hermenêutico, já que permite analisar alguns fatos específicos - que foram reconhecidos sem intenção — com o objetivo de situar o conceito de pós-verdade em um contexto político e conjuntural em vários espaços geográficos do mundo. Por sua vez, esses espaços são interpretados à luz da filosofia pós-moderna e da reflexão crítica. Uma das reflexões mais importantes da pesquisa se refere à pretendida objetividade da epistemologia tradicional, enfraquecida de forma acelerada diante do fato de que os sistemas de crenças vêm ganhando força da cidadania. Esses sistemas resumem certezas no imaginário coletivo, no domínio e no conhecimento da realidade, dos fatos, dos sentimentos e das intenções das pessoas independentemente do que os julgamentos correspondam ou não às coisas. Dessa maneira, é permitido prever que esses sistemas de crenças desviam o ser humano, o cidadão comum, da realidade objetiva, o que o afasta de um verdadeiro pensamento crítico.

Palavras-chave: pós-verdade; niilismo; transparência; pós-modernidade; verdade; poder; vontade. 


\section{Introducción}

El fenómeno de la posverdad se nos presenta como un terreno fértil que ha permitido un ejercicio de análisis filosófico a partir de algunas ideas de Nietzsche y Foucault sobre las formas de verdad. Estas ideas están relacionadas con otros pensadores contemporáneos como Vattimo y Lyotard, quienes disciernen sobre la época en la que se desenvuelven estos acontecimientos. Luego se discute la posibilidad de que la actual sociedad sea una sociedad transparente que pierde sentido al eliminar toda negatividad, tal como afirma el pensador contemporáneo surcoreano Byung-Chul Han (2013) en su obra La sociedad de la transparencia.

La aparición del neologismo posverdad está enmarcada en unos acontecimientos históricos claroscuros. Aunque no hay un consenso sobre su categoría, su estudio resulta importante para la filosofía, ya que permite identificar y profundizar este fenómeno de manera crítica en relación con la utilización de los medios de comunicación masiva como canales que afectan indirectamente a las democracias. Este fenómeno crea tendencias de pensamiento mentirosas en la colectividad de los sujetos que se potencializan a través de las redes sociales, bien sea de manera inconsciente o consciente, e influyen en la construcción y posible manipulación de la opinión pública. En este sentido, García (2019), en Redes sociales e interés político: frecuencia con la que se comparte información sin confirmar en Quito, menciona un estudio de Vosoughi, Roy y Aral que se realizó en el 2017:

El estudio "The spread of true and false news online" (difusión de noticias verdaderas y falsas en línea), resultado del análisis de 126.000 historias compartidas en Twitter entre los años 2006 y 2017 con más de 4,5 millones de tuits en inglés, emitidos por 3 millones de personas aproximadamente, concluye que las mentiras se dispersan rápidamente porque provocan respuestas de temor, indignación y sorpresa, mientras que las verdades provocan tristeza, confianza o anticipación. (p. 243)

Este estudio muestra, según García (2019), que

la información falsa se difunde en mayor cantidad, rapidez y llega más lejos, más rápido, con mayor profundidad y más ampliamente que la información verdadera. Las noticias falsas que están relacionadas con política tienen efectos más marcados que cuando están relacionadas con temas más sensibles como terrorismo, desastres naturales, información financiera, leyendas urbanas, entre otras. (p. 243)

Con lo anterior podemos entender los principios de funcionamiento y la forma en que se manipulan las reacciones de los receptores según estímulos específicos. Esto es algo que la publicidad conoce desde hace bastante tiempo, lo que refuerza nuestra idea original sobre la aceptación y difusión de información en redes bajo criterios emocionales. 
Por otra parte, la posverdad también es analizada desde una perspectiva social y filosófica. En este sentido, se entiende como un fenómeno y no como una mentira aislada, tal como escribe Carrera (2018):

El concepto de posverdad se ha convertido en un lugar común, en una palabra, de moda que se usa para denominar tanto la supuesta superación de un estado previo en el que, al parecer, la verdad era la norma, como para legitimar determinados procedimientos que tienen mucho más que ver con la esfera del poder (incluido el discursivo) que con la de la verdad. (p. 7)

\section{Metodología}

La metodología de este trabajo tiene un enfoque cualitativo. Parte de la hipótesis de que las redes sociales construyen identidades colectivas que crean imaginarios equívocos con relación a la realidad sociopolítica mundial. A la postre, estas redes degradan las democracias cuando crean tendencias negativas en las redes sociales con un lenguaje violento que incita a la violencia y que, sobre todo, excluye el pensamiento diferente, critico, disidente o divergente.

A partir del método hermenéutico, se estudió el concepto de verdad. En este sentido, se toman elementos de los filósofos contemporáneos Friedrich Nietzsche y Michel Foucault. De igual forma, es importante destacar algunos lineamientos a partir de otros filósofos como Jean-François Lyotard, Jean Baudrillard y Gianni Vattimo, cuyas ideas contribuyen al sustento argumentativo de la investigación.

También es importante analizar el fenómeno de la posverdad en relación con las redes sociales, la mediatización del discurso político, la cuestión de la verdad en sentido ético en la esfera política y la proliferación de la opinión pública. Estas redes sociales funcionan como el sitio de verificación en donde surge el problema de la desinformación, el cual da paso a este clímax de sinsabor y apatía hacia las instituciones estatales y privadas. De ahí se llega a la conclusión de que hoy se está plasmando una sociedad de la transparencia que surge, como se explicará a continuación, por el acelerado proceso de cambio de paradigma de información en una sociedad moderna que reconocía la presencia de la negatividad, pero que ahora tiende a eliminar. La posverdad quedará plasmada como estratagema retórica de los discursos políticos, económicos, sociales y culturales en la construcción de tendencias e identidades colectivas.

Se identificaron las diferentes prácticas sociales de la posverdad en la crisis de pérdida de identidades y los valores que degradan las sociedades democráticas. Lo novedoso en esta "era de la posverdad", como la han denominado varios críticos y filósofos como Gabriela Bianco, Manuel Arias, Gianni Ferrari, entre otros, es la proliferación de la opinión pública a través de los medios comunicación masiva y en especial 
las redes sociales. Estos autores han expresado que las redes sociales aíslan a los individuos y los ubican en un sitio de confort en donde se comunican con quienes piensan como ellos, es decir, se crean perfiles comunes donde el sujeto se afirma en sus creencias. Presenciamos una crisis de la verdad, la democracia y la confianza que trasciende las urgencias de la actualidad. En este contexto, González, Pérez y Verdecia (2018) comentan que:

En la era digital con el uso desmedido de la información el individuo se convierte en autómata, necesita de más información que unido a la inmediatez debe valorar de acuerdo a su nivel cultural, lo verdadero de lo falso [...] los servidores como Facebook envían a cada uno aquella información que responde a sus necesidades y a su interés, de manera que el sujeto vive definitivamente atrapado en una campana o una burbuja de la que no necesita y en realidad no puede salir. En ese ámbito todos los datos y las comunicaciones que recibe están destinados a reforzar sus aficiones, sus intereses y sus opiniones. La exposición a ideas contrarias a su propia posición sobre cualquier asunto considerado de interés general, no existe porque, o estas ideas no aparecen en su burbuja o lo hacen para ser desacreditadas. (p. 12)

Las redes sociales encapsulan al individuo en una especie de burbuja, que es el "encierro de lo propio", como lo afirma Han (2017). Esta burbuja impide establecer diálogo con otros que piensen de manera diferente. En este sentido, las redes sociales aíslan en vez de asociar a los seres humanos. Monasterio (2018) afirma que:

las redes sociales basadas en Internet como Facebook, nos ofrecen la oportunidad de saber lo que otros opinan y en última instancia nos afecta. Nos juntamos con aquellas personas que piensan similar a nosotros con lo cual esto produce efectos de selección y sesgos de confirmación que conducen a solo aceptar aquella información que viene a reforzar lo que ya creemos. (p. 12)

Pero no todo se trata de manipulación. Existe un cambio en la percepción de la realidad del sujeto contemporáneo. Este tiende a desmentir la realidad: los sujetos de la información masiva tienden a considerar lo real como algo que no es objetivo ni está basado en hechos concretos. Por el contrario, consideran la posibilidad de construcciones simbólicas alejadas de lo objetivo. De esta manera, se crea conciencia tanto individual como colectiva. Pero el problema es la forma en que se crea esta conciencia.

Hoy se piensa el mundo de manera distinta a la modernidad. A partir de la puesta en escena de las ideas de Nietzsche (2012) sobre la muerte de Dios, se abre un mundo de posibilidades en el que la verdad se pelea con todo. La verdad quiere legitimar todo orden, así lo dicen algunos pensadores como Vattimo (1996). Este autor considera que toda la historia se ha transformado en lenguaje e imágenes, y que lo realmente importante es realizar una deconstrucción simbólica de la realidad. Se rechaza, en- 
tonces, el racionalismo, con lo cual se fragmenta nuestro entorno, nuestro mundo y nuestro universo simbólico.

La historia podría devenir, como lo diría Nietzsche (2006), en miradas parciales, en perspectivismo. Para Nietzsche, por ejemplo, no hay nada estable. Nuestra modernidad está atravesada por esas ideas que expresan de manera tácita este fenómeno de la posverdad. ¿Estamos acaso frente a un fenómeno que intenta dominar y legitimarse al mismo tiempo? Tal como lo piensa Manrique (2016),

Michel Foucault insiste en que "la verdad" es "la especie" que legitima el poder de turno. La narración, para él, importa más que la realidad de los hechos: al mercado interesa la posibilidad de venta y al poder la satisfacción de sus intereses. (p. 164)

El hombre se encuentra frente a un cambio de paradigma y es inconsciente de este. Podríamos decir, por ejemplo, que ya no se trata del "pienso, luego existo" cartesiano, sino del "creo, luego soy". Esta tendencia provoca una especie de acción colectiva motivada, en gran medida, por las emociones y la falta de pensamiento crítico de los individuos que están lejos de entender la realidad; es esto lo que precisamente buscan quienes se valen de la posverdad. No se reflexiona ni se consideran los datos objetivos porque, como se ha dicho anteriormente, los individuos de la masa virtual no están interesados más que en sus propias ideas y en las de aquellos que piensen de la misma manera que su grupo o comunidad virtual. Es una especie de relación perversa entre violencia, medios y política que crea personajes que llegan a las audiencias vacíos de contenido.

\section{Concepto de verdad en Nietzsche a partir del nihilismo, la muerte de Dios y el superhombre}

Para Nietzsche (2015), la verdad es una convención "fabricada a partir de conceptos" o "pactos" que hacen los hombres como forma de ordenar más o menos las sociedades, lo cual termina siendo una mentira colectiva. Sus pensamientos se acentúan en la idea de que, en un estado natural, los hombres conviven inclinados por una necesidad: "por necesidad como por aburrimiento, desea existir en sociedad" (Nietzsche, 2015). Como indica Nietzsche, es una necesidad de supervivencia. En este sentido, se crean los lazos de amistad solamente por mantenerse vivos frente a los otros que amenazan constantemente. De ahí que el hombre utilice su intelecto para "fingir" y procurar un estado de paz con el único propósito de conservarse como especie "y gregariamente, precisa de un tratado de paz" (Nietzsche, 2015). En este sentido, Nietzsche (2012) continúa resaltando, en su ensayo Sobre verdad y mentira en sentido extramoral, que:

Este tratado de paz conlleva algo que promete ser el primer paso para la consecución de ese enigmático impulso hacia la verdad. Porque en este momento 
se fija lo que desde entonces debe ser verdad, es decir, se ha inventado una designación de las cosas uniformemente válida y obligatoria, y el poder legislativo del lenguaje proporciona también las primeras leyes de la verdad, pues aquí se origina por primera vez el contraste entre verdad y mentira. (p. 16)

De esta manera, Nietzsche describe el lenguaje como una manifestación del instinto de verdad, esto es, como un deber moral que las sociedades se imponen para su supervivencia y como una categoría que inventó el hombre para establecer un or den dentro de los términos de una verdad convencional y útil al colectivo social. Esto quiere decir que la primera fórmula de su teoría consiste en que el entendimiento es un medio al servicio de la adaptación y del dominio, y que el objetivo último del conocimiento no es la búsqueda de la verdad absoluta, sino del control social: la voluntad de poder.

A partir de las ideas de Nietzsche expuestas, se puede establecer una relación fundamental con la investigación que se sigue al aclarar que existen determinados dominios de saber que se configurarán a partir de múltiples relaciones de poder en la sociedad. De esta manera, se crea un nuevo sujeto de conocimiento, tal como lo expresó Michael Foucault (1978) en su serie de conferencias de 1973, publicadas en el libro La verdad y sus formas jurídicas.

Cabe destacar que Nietzsche discrimina, además, dos formas de nihilismo. El primero, el nihilismo activo, ataca con violencia todo ideal, toda forma de coacción sobre el individuo al que llama. El segundo es el nihilismo pasivo. Este no ataca y es considerado como un síntoma de decadencia. En este sentido, Nietzsche (2006) define el nihilismo pasivo

[c]omo un signo de debilidad; la fuerza del espíritu puede estar cansada, agotada, de manera tal que las metas y los valores existentes hasta el momento son inadecuados y no encuentran ya crédito. Que se disuelve la síntesis de valores y metas (sobre la que descansa toda cultura fuerte), de manera tal que los diferentes valores se hacen la guerra: descomposición. Que todo lo que reconforta, cura, anestesia, pasa al primer plano, bajo diferentes disfraces, con carácter religioso, o moral o político o estético etc. (p. 256)

Para Nietzsche, el nihilismo activo es una nueva forma de mirar el mundo, examinar a fondo el verdadero valor de las cosas, tener pensamiento crítico, reflexionar, tener consciencia del estado del ser y de las cosas. En definitiva, esta especie de nihilismo termina siendo un antinihilismo por sus propias características. Se afirmaría, entonces, la voluntad de poder que consiste en un "conjunto de todas las manifestaciones vitales" (Nietzsche, 2006, p. 257). Este nihilismo activo está al servicio de la vida, de esta vida concreta y real, y no de una vida más allá o fuera de nosotros. Esto quiere decir que no está al servicio de ninguna metafísica, religión, ciencia o cualquier otra cosa, sino solo a lo vital. 
En este punto nos preocupa — y se advierte — que la realidad irreal o virtual de las redes sociales, que es donde discurren ahora ciertas formas de verdad del sujeto, se convierta en una forma nueva de nihilismo negativo que, aunque no niegue, olvide por preferencia algunos aspectos la vida real.

El filósofo colombiano José Ferro (2004) expone en el libro El retorno de la metáfora que, con la muerte de Dios, Nietzsche marca el fin del idealismo, de todo dogma, de toda ilusión de creer en un más allá incierto. Con la muerte de dios, Nietzsche da vuelta a la tierra y comienza a sembrar la semilla de la voluntad de poder que recogerá como fruto el superhombre. En este sentido, enseña que el hombre es algo ya superado y que debe ser superado. De esta manera, le devuelve el verdadero sentido a la tierra. Dice que el superhombre es un mar, y resalta la figura del mar inmenso como creación (Ferro, 2004).

En últimas, el superhombre es el que destruye toda la moral y la epistemología occidental creando una nueva visión de la realidad. El superhombre es el que rompe los esquemas y normas porque conoce que la realidad y la historia es diferente a lo que se le impone de afuera. Así lo expresa Nietzsche (2003) en el Zaratrusta:

Antes se decía Dios cuando se miraba a los mares lejanos, pero ahora he enseñado a decir: superhombre (übermensh). El decir (sagen) es creación; y Zaratustra sueña en sus discípulos que podrán crear; «¿podríais crear un Dios? (einGottschaffen).» Ahora, en lugar de hablar de los dioses, «"vosotros podréis crear al superhombre (den übermenschenschaffen)», porque es la más alta realidad, la figura superior que se encuentra en un lejano porvenir más allá de todo hombre. Invitación a crear de su propia plenitud, como un reto a la indigencia del arquitecto racionalista que levanta un templum de conceptos para conjurar a un dios conceptual bajo un cielo de concepto. (Nietzsche, 2003, p. 117)

Carvalho (1994) opina sobre esto que "con la eliminación de valores transcendentes, Nietzsche elimina cualquier sombra de platonismo que siempre resurge en las varias formas de oposición entre un mundo verdadero y un mundo aparente" (p. 15).

\section{Concepto de verdad según Michel Foucault en relación con el nihilismo nietzscheano y su incidencia en la posverdad}

Foucault (1978) indaga, por su parte, a través de su método arqueológico, una historia de la verdad y la manera en que se constituyeron diversos regímenes de verdad mediante la relación saber-poder.

Foucault (1992) prepondera en su discurso que existen procedimientos de control que son evidentes en nuestras sociedades, y los distingue en tres grupos. El primer grupo abarca los procedimientos de exclusión que son de carácter externo y que 
afectan al discurso: su función es dominar los poderes que los discursos conllevan, entre estos cabe destacar la prohibición. En este sentido, Foucault (1987) afirma que el individuo está cohibido por circunstancias internas o externas: "Uno sabe que no tiene derecho a decirlo todo, que no se puede hablar de todo en cualquier circunstancia, que cualquiera, en fin, no puede hablar de cualquier cosa" (p. 14). Foucault (1987) continúa en esta misma línea cuando afirma:

El anterior mecanismo se da a través del tabú del objeto, del ritual de la circunstancia y del derecho exclusivo del sujeto que habla. Un juego de prohibiciones que se mezclan unos con otros y se refuerzan para formar una malla que se va desplazando. Esa malla se comprime cada vez más en ciertas regiones, a saber: la sexualidad y la política. (p. 15)

En este trabajo analizamos el campo de la política, en donde los discursos se ejercen de manera privilegiada y se establece un vínculo con el poder. Foucault ofrece esta delimitación, pues para él existe una prohibición que convierte al discurso en objeto de las luchas políticas. En este sentido, para Foucault (1987), el "discurso no es simplemente aquello que traduce las luchas o los sistemas de dominación, sino aquello por lo que, y por medio de lo cual se lucha, aquel poder del que quiere uno adueñarse" (p. 15).

El segundo principio de exclusión tiene que ver con la separación y el rechazo. Para ejemplificar este principio, propone la oposición entre razón y locura que examina desde la Edad Media. El discurso del loco no podía discurrir como el de los demás, ya que toda palabra de su boca era nula y sin ningún tipo de valor. Por esta razón, ni siquiera podía testimoniar ante la justicia ni autentificar una partida o contrato.

Foucault (1987) sostiene que en el propio discurso se reconocía la locura: "Ellas eran el lugar en que se ejercía la separación, pero nunca eran recogidas o escuchadas" (p. 16).

Por último, está el grupo de la oposición entre lo verdadero y lo falso. A través de la propia historia como separación, han dado forma a nuestra voluntad de saber, es decir, a los discursos ligados al ejercicio del poder que no han dejado de desplazarse desde la gran separación platónica. Esta voluntad de saber se apoya en la institucionalidad que se refuerza, a la vez, por ciertas prácticas como la pedagogía, los laboratorios y las sociedades de sabios. Pero esta también es acompañada "Iplor la forma que tiene el saber de ponerse en práctica en una sociedad, en la que es valorado, distribuido, repartido y en cierta forma atribuido" (Foucault, 1987, p. 22).

En última, los análisis de Foucault hacen sospechar acerca de si esta clase de voluntad en realidad lo que hace es ejercer presión sobre los otros discursos. Para ello, toma como ejemplo las prácticas económicas, políticas, penales, religiosas y literarias; en este sentido han pretendido fundarse y racionalizarse. La voluntad de 
verdad ha sido impuesta y por tal motivo enmascara la verdad que quiere. La verdad termina siendo ese conjunto de reglas en las que se discrimina lo verdadero de lo falso. Pero, además, se relaciona lo verdadero con los efectos políticos del poder. En este sentido, los sistemas de enunciados de poder tienen la obligación de decidir qué es lo verdadero y qué no lo es.

En este sentido, Foucault (1987) piensa que "Illa verdad apoyada por sistemas de poder, produce pues la realidad de lo que no existe, obligando a las existencias materiales a que se parezcan a esa realidad" (p. 22).

Esta conclusión foucaultiana es importante para este trabajo porque las redes sociales podrían llegar a ser, o son, parte de esos sistemas de poder. Se podría llegar a pensar que la verdad está en manos del poder, de las instituciones - prodigiosas maquinarias destinadas a excluir-, y que el poder no está ubicado en determinado espacio o cuerpo, sino que está distribuido en todo el cuerpo social.

Para Foucault (1978), el poder y la verdad, siempre se van desplazando a otros territorios, van buscando nuevos objetos. En este sentido, en nuestra sociedad de la información y la era de la posverdad, el discurso político se ha empoderado. Además, ha realizado lo que Foucault llamaría, en un primer momento, una función constrictiva, en tanto opera desde la exterioridad del discurso hacia los sujetos de la información. Estos terminan convencidos por necesidad de deseo y poder; se convierten, finalmente, en sujetos sin capacidad de pensar y de fácil manipulación. La noción de posverdad, como herramienta para los discursos políticos, aleja al sujeto de la realidad y mantiene su propio mundo de imágenes, tal vez erróneas, dentro de un mundo totalmente distinto.

\section{Resultados}

Luego de cotejar y analizar los metadatos, así como de interpretar a través del método hermenéutico, se podría concluir, entre otras cosas, que la actual sociedad de la información pretende cuestionar la realidad, dudar de todo cuanto existe, incluyendo la manera de hacer política en nuestros días. De hecho, se duda especialmente de los discursos políticos porque terminan siendo un engaño. De ahí que sea importante pensar en maneras de reivindicar la política y la democracia a través de consensos; los filósofos están llamados a realizar esta tarea.

Uno de los resultados de esta investigación consiste en propiciar una búsqueda de sentido de pertenencia y concientización mediante el control de los medios de comunicación y la sanción a quienes emitan noticias falsas; en fin, se precisa de una repolitización que conduzca a la búsqueda de un sentido global y a un mejoramiento de nuestra democracia. 
Entendimos que Nietzsche (2012) destaca la imperante necesidad de la transformación del sujeto a partir del anuncio de la muerte de Dios. Según Vattimo (1996), con la muerte de Dios, Nietzsche aniquila la creencia en el ser, es decir, se da fin a la metafísica. En este sentido, sus análisis conducen a la negación de la realidad tal como se había conocido hasta el momento, pues esta estaba basada en supuestos históricos. Lyotard denominó estos supuestos, inspirado en Nietzsche, como metarrelatos, pues este ya había expresado la muerte de los grandes metarrelatos o las ideologías de Occidente que se apoyaban en el platonismo y el cristianismo. Pero Lyotard desarrolló, de una manera más teórica, el concepto de fin de la modernidad o posmodernidad como destrucción de los grandes relatos históricos, cuya moda terminó siendo un neologismo muy usado por parte de artistas, científicos, políticos, entre otros. Sobre esto, Anderson (2000) sostiene:

La primera obra filosófica que adoptó la noción fue la condition postmoderne, de Jean-François Lyotard, publicada en 1979 en París. [... Lyotard declaró que "La apuesta de la posmodernidad como un todo" no era "exhibir la verdad dentro del cierre de la representación, sino plantear perspectivas dentro del retorno de la voluntad", alabando la famosa película experimental de Michael Snow que mostraba un paisaje vacío de Canadá, filmado por una cámara giratoria inmóvil, y las proyecciones espaciales de Duchamp. (p. 32)

La posmodernidad, que es la época en la que nos encontramos, está marcada por el final de estos grandes metarrelatos. Estos se comenzaron a criticar a partir de la obra de Nietzsche. Esta crítica tomó fuerzas a mediados del siglo XX con la recepción del pensamiento del francés.

Pero Nietzsche no fue el único en abrir el debate ni sus ideas fueron las verdaderas demoledoras de las antiguas ideologías. Según Lyotard (1987), estas "habían sido destruidas por el desarrollo inmanente de las propias ciencias" (p. 39). La posmodernidad, en la que las fuerzas productivas y el reciente capitalismo reducían todo conocimiento a lo puramente performativo, era una especie de relación maquinal entre las ciencias y el poder. Las tecnociencias desarrolladas aplican el modelo de deconstrucción, lo cual se puede comprobar en el hecho de que la física, por ejemplo, da paso a la microfísica; se teoriza sobre el caos, sobre el fragmento, y las ciencias biológicas mucho tiempo después descubrirán el genoma humano. Con ello, se dio una revolución científica cuyos cimientos se formaron debido a las descripciones que, grosso modo, han sido expuestas hasta el momento.

Byung-Chul Han (2013) realiza una crítica al concepto de transparencia porque sabe y reconoce que es negativo fuera del ámbito político. La sociedad de la transparencia florece cuando se pierde la confianza, esto es, cuando se niega al otro en nombre de una confianza que se positiviza. De esta manera, la confianza recurre a la vigilancia y al control, y termina siendo "un infierno de lo igual" (Han, 2017) que conduce a la sociedad del cansancio. Con respecto a esto, Han (2013) dice: 
En la panóptica digital no es posible ninguna confianza, y ni siquiera es necesaria. La confianza es un acto de fe, que queda obsoleto ante informaciones fácilmente disponibles. La sociedad de la información desacredita toda fe. La confianza hace posibles las relaciones con otros sin conocimiento exacto de estas. La posibilidad de una obtención fácil y rápida de información es perjudicial a la confianza. Desde este punto de vista, la crisis actual de la confianza se debe a los medios de comunicación. (p. 99)

La transparencia, según Han (2013), tiene varios elementos: la exposición, la evidencia, la pornografía, la aceleración, la intimidad, la información, la revelación y el control. Estos elementos, en su conjunto, se vuelven transparentes en tanto no son sometidos a la lupa de la crítica. No tienen resistencia alguna porque todo se allana dentro del capital, la proliferación de informaciones y la comunicación de masas (Han, 2013).

La sociedad de la transparencia expone lo otro y lo hace visible. Sin embargo, no lo somete a crítica. Esta ausencia de crítica es lo que provoca, según Han (2013), la crisis actual que está determinada por la aceleración de la información. La sociedad de la transparencia actual es positiva en tanto genera violencia como resultado de la hiperinformación y la variedad de informaciones. En este sentido, se pelea con la verdad que desea mantener su estatus y homogeneizarlo todo. Aguilar (2011) argumenta esta visión de la realidad cuando afirma:

La realidad virtual se está imponiendo sobre la realidad real, el tiempo es atemporal, el espacio es inmaterial, la historia sin secuencias. Valores e intereses son creados sin referencia al pasado o al futuro. Lo que aparece en las pantallas es lo real, no lo que experimentamos. (p. 19)

Ya no es disciplinaria, como se explicó a partir de Foucault (1978), sino que es una sociedad del rendimiento. Esta sociedad está marcada por el consumismo. Por ello, los dispositivos de control son otros y cumplen otra función en relación con la economía de consumo.

En esta sociedad de la transparencia no existe espacio de contemplación. A falta de pensamiento crítico - y es esto lo que provoca las tendencias colectivistas y negativas en las redes sociales-, degrada las democracias, pues las conciencias de los ciudadanos se colocan en extremos manejables de la verdad. Y esta verdad está en manos de grupos de poder. Javier Lomelí (2019) sostiene que

[n]uestros afectos y pasiones influyen en nuestra razón y normalmente nuestras filiaciones políticas tienen un lado afectivo indiscutible. En ese sentido, nuestra noción de verdad se encuentra siempre influenciada por nuestro lado emocional e inconsciente. Eso lo sabe perfectamente la mercadotecnia en general, y la mercadotecnia política en particular. (p. 34) 
En la era de la posverdad, la función simbólica consiste en hacer desaparecer la realidad, ocultarla o enmascararla para ofrecer una ilusión. Pero lo más grave de todo es que pretende ocultar tal enmascaramiento, es decir, intenta hacer pasar por verdadero lo que no lo es.

\section{Discusión y conclusiones}

Estamos en un mundo mediatizado por noticias, muchas veces falsas, que obedecen a un sistema consumista y capitalista en el que la competencia es un elemento importante, y este afán se refleja en los medios de comunicación. En la competencia del mercado y en el modelo neoliberal, las noticias fluyen a través de los medios de comunicación masiva y de las redes sociales como si fuera pólvora. De esta manera, crea una ilusión de libertades a la hora de conformar la opinión pública, pero de manera inconsciente para los sujetos de la información. Como dice Han (2013), "llla libertad de la que hace gala el neoliberalismo es propaganda" (p. 86).

La posverdad no permite contemplar el mundo porque el sujeto, sin capacidad de crítica y preso de la información, es absorbido por la misma información. Existe una aniquilación de nuestro espíritu crítico y la individualidad en el sentido de que la opinión se torna muy efímera. Además, la posverdad coacciona las libertades en general, ya que, a través de las redes sociales, se van creando formatos de pensamientos que obedecen — quizá inconscientemente- a ideologías o intereses de grupos de poder. Estamos en una sociedad de la hipercomunicación que nos conduce, como lo afirma Han (2017), a la proliferación de lo igual. Lo ideal para los grupos de poder es la reproducción de formas idénticas de pensamiento acrítico por parte de las masas que consumen información a gran escala de emisores, cuyos intereses se confunden entre toneladas ingentes de información parcializada.

En definitiva, el sujeto actual se moviliza acérrimamente, pero muy rápido, entre dos mundos: uno real y otro aparente. Este último gana terreno, ya que la verdad es inmediata; siempre aterroriza a quien capta la atención porque la aprehende y repite de una manera inconsciente en tanto los mensajes son más persuasivos. En este contexto, el sujeto no propende por el conocimiento que emerge de las redes sociales ni intenta evadir la información. Todo lo contrario, le da más rienda suelta a sus emociones y creencias que a los datos objetivos. Confía en un sistema del que se alimenta y que oculta, incluso, un poder de dominación blando que se mimetiza en el aparente confort de las redes sociales. Estas le dicen al oído lo que el sujeto — ciudadanoquiere escuchar y la manera en que debe hacerlo.

La sociedad de la transparencia es el reino del rechazo de lo ajeno. En este sentido, la negatividad o la eliminación de lo distinto carece de sentido, ya que nos produce la ilusión de realizarnos como individuos. Pero lo que en realidad hacemos es imposibilitar el diálogo y el consenso entre todos. 
Estamos frente a un presente caótico que se entrega a la simulación gracias a los medios masivos y a las redes sociales, que son los dispositivos en donde se concentran y emergen las tendencias a eliminar lo otro. Así, se crea un entorno totalmente positivo del poder. Creemos que el pensamiento se fragmenta diametralmente debido a la proliferación y consumo masivo de noticias que se publican. Las noticias falsas, los medios de comunicación, entre otros, crean y reproducen la opinión pública, así como encasillan a los sujetos en una manera de pensar de acuerdo con los intereses de unos pocos. Es la misma moral de rebaño que Nietzsche (2015) nos reveló en La genealogía de la moral, porque ahora estamos en un sistema dominado por lo idéntico. Solo existe resistencia hacia lo extraño. Pero sin lo extraño no hay posibilidad de contradicciones, disidencias, contrastes, lucha y cambio, como lo expusimos en el capítulo sobre Nietzsche.

En la actualidad, el sujeto de obediencia pasó a ser un sujeto del rendimiento; está marcado por su productividad y rapidez en un mundo globalizado.

Los sujetos receptores de la información no miran los mensajes en contexto, sino de manera fragmentada. Solo asumen posición frente a las noticias que son afines a los perfiles que las redes sociales construyen mediante algoritmos informáticos que atomizan a los sujetos. El fenómeno de la posverdad funciona, entonces, como una herramienta estratégica para manipular. Esta manipulación se da especialmente en los discursos políticos para captar adeptos; es una forma deliberada de organizar la información a través de las redes, muy a pesar de que estas no constituyen un poder aislado. Sin embargo, Han (2017) afirma:

Los medios pueden ser confiscados por acciones de la estrategia del poder, desestabilizándolo. Precisamente por este motivo el poder totalitario trata de ocupar los espacios mediales. Y no cabe pensar la formación de una opinión pública separada del desarrollo de los medios de información. (p. 122)

Las redes sociales se convierten en espacios de poder. Allí se genera la cuestión de hacer política hoy a través de la reorganización de la opinión pública. En este sentido, se concluye que las redes sociales funcionan como burbujas que encapsulan identidades parecidas o idénticas para crear ilusiones de una aparente unificación de ideas, las cuales están lejos de crear un verdadero desarrollo de pensamiento crítico. En el trabajo cuantitativo realizado por Sánchez y Pinochet (2017) se corrobora la afirmación anterior:

El análisis de la Fan Page resulta ser un indicador de la importancia que asigna la organización a la gestión de las redes sociales. Por ejemplo, la frecuencia de actualización y el tiempo de respuesta a consultas reflejan este aspecto. Además, es posible describir la conducta de los usuarios, incluyendo cómo se involucran con los Posts y cuáles de estos actores resulta ser más 
promisorios para incrementar la popularidad de una Fan Page. A partir de cada fan page de interés, se construye una red en la cual los nodos corresponden con usuarios y se conectan los usuarios que indicaron "Me gusta" o hicieron comentarios sobre el mismo Post [sic]. (p. 14)

La llegada de la posverdad ha implicado pobreza intelectual, falta de contemplación y de análisis; el pensamiento profundo queda aniquilado por el exceso de positividad. El pensamiento mismo se reduce cálculo una vez más. Además, si es cierto que se elimina lo otro, lo distinto, la negatividad, entonces no queda nada más que un pensamiento propio y egoísta que no permite dar el paso hacia el pensamiento del afuera, hacia una dialéctica que logre la articulación, el consenso, el debate, en fin, el sentido de la historia. Efectivamente, los discursos políticos en el contexto de la era de la posverdad crean y potencializan esos perfiles que, a su vez, atentan contra las democracias en tanto polarizan a un país. Las redes sociales configuran esas tendencias colectivas que no dejan pensar de manera distinta. En este sentido, los poderes intrínsecos que se estudiaron antes en este trabajo, actúan y se aprovechan de esta situación como si literalmente fueran medios. De esta manera, se olvida el fin y el deber ser de estos, el cual consiste en la configuración y regulación de la realidad desde una óptica razonable para el bienestar de las sociedades que genere y construya democracia. Pero esta democracia, a su vez, se degenera cuando inclina sus objetivos hacia el interés de unos pocos, en detrimento del interés y el bienestar general de la mayoría. En La política de Aristóteles (IV a. C), este movimiento de degeneración de la democracia conduce a la demagogia, esto es, el poder ejercido y obtenido a través de la adulación del pueblo. Este es un concepto bastante cercano a nuestro problema de interés. En la posverdad, alguna forma de poder reproduce lo que el cuerpo social quiere escuchar. Este hecho afirma e inscribe al sujeto en una forma parcializada del mundo que no atenta contra sus creencias y en donde se siente seguro.

Se podría concluir que la posverdad ha desplazado la clásica manera de entender la realidad y de concebir la verdad. Esta ya no se percibe como algo estable y duradero, sino como una zona de confort donde confluyen creencias y opiniones personales, y en donde las emociones y los sentimientos personales juegan un papel preponderante.

Asimismo, comprendemos que la posverdad está mediada por un tipo poder. En este caso, son los medios de comunicación los que permiten y potencian la consolidación de la opinión pública. A su vez, estos excluyen al ciudadano que tiene pensamientos o creencias diferentes a las del cuerpo social.

Nos preocupa y advertimos que la realidad irreal de las redes sociales, que es donde ahora discurren ciertas formas de la verdad del sujeto, se convierta en una forma nueva de nihilismo que, aunque no niegue, olvide algunos aspectos la vida real por preferencia o placer. 
Finalmente, el análisis de la posverdad nos muestra que nada es verdad para siempre. Antes bien, la verdad es ahora la suma de parcialidades. Pero esas parcialidades están en las manos de quienes concentran el poder.

\section{Referencias}

Aguilar, F. (2011). Reflexiones filosóficas sobre las tecnologías y sus nuevos escenarios. Conrado, 15(70), 109-119.

Anderson, P. (2016). Los orígenes de la posmodernidad. Akal.

Carrera, P. (2018): Estratagemas de la posverdad. Revista Latina de Comunicación Social, 73, 1469-1482.

Carvalho, J. (1994) La antropología y el nihilismo filosófico posmoderno. Alteridades, 4(8), 13-29.

Ferro, J. (2004). Nietzsche y el retorno de la metáfora. Ediciones Uninorte.

Foucault, M. (1978). La verdad y sus formas jurídicas. Gedisa.

Foucault, Michel (1987). "El poder y la norma" en Discurso, poder, sujeto. Lecturas sobre Michel Foucault. Universidad de Santiago de Compostela.

Foucault, M. (1992). El orden del discurso. Tusquets Editores.

García, J. E. (2019). Redes Sociales e interés político: frecuencia con la que se comparte información sin confirmar en Quito. Icono, 14-17(2), 231-253.

González, N., Pérez, F. y Verdecia, P. (2018). La posverdad en la era de las tecnologías las informáticas y las comunicaciones. Revista Caribeña de Ciencias Sociales, 2-15.

Han, B. (2013). La sociedad de la transparencia. Herder.

Han, B. (2017). La expulsión de lo distinto. Herder.

Lomelí, J. (2019) Posverdad y Psicopolítica. Revista Colombiana de Humanidades, 51(95), 347-364.

Lyotard, J.F. (1987). La posmodernidad (explicada a los niños). Barcelona, España: Gedisa.

Manrique, J. (2016). Populismo y posverdad. Inmanencia, 5(1), 161-165.

Monasterio, A. (2018). Internet y cognición social. Revista de Humanidades, (33), 115-130.

Nietzsche, F. (2003). Así hablaba Zaratustra. Ediciones Esquilo.

Nietzsche, F. (2006) Fragmentos póstumos. Tecnos.

Nietzsche, F. (2006). Nihilismo: Escritos póstumos (edición de Gonçal Mayos). Península.

Nietzsche, F. (2012). Sobre verdad y mentira en sentido extramoral. Tecnos.

Nietzsche, F. (2015). La genealogía de la moral. Tecnos.

Sánchez, M. y Pinochet, G. (2017). El rol de las redes sociales virtuales en la difusión de información y conocimiento: estudio de casos. Universidad y Empresa, 19(32), 107-135.

Vattimo, G. (1996). Creer que se cree. Editorial Paidós. 